\title{
Photocatalytic ozonation under visible light for the remediation of water effluents and its integration with an electro-membrane bioreactor
}

\author{
Diego Toledano Garcia ${ }^{a}$, Lütfiye Y. Ozer ${ }^{a}$, Francesco Parrino ${ }^{b}$, Menatalla Ahmed ${ }^{a}$, \\ Grzegorz Przemyslaw Brudecki ${ }^{\mathrm{c}}$, Shadi W. Hasan ${ }^{\mathrm{a}}$, Giovanni Palmisano ${ }^{\text {a, }}$ \\ a Department of Chemical Engineering, Khalifa University of Science and Technology, Masdar City, PO BOX 54224, Abu Dhabi, United Arab Emirates \\ ${ }^{\mathrm{b}}$ Dipartimento di Energia, Ingegneria dell'Informazione e Modelli Matematici (DEIM), University of Palermo, Viale delle Scienze Ed. 6, Palermo, 90128, Italy

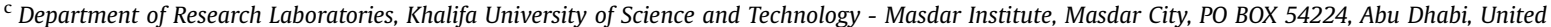 \\ Arab Emirates
}

\section{H I G H L I G H T S}

- Photocatalytic ozonation under visible light degraded 4-nitrophenol.

- Photocatalytic ozonation under visible radiation and eMBR were applied to remediation of grey water.

- Ozonation boosts photocatalysis under visible radiation if a sufficient radiation is applied.

- TOC content of real effluent is abated by ca. $60 \%$, the total bacterial count by ca. $97 \%$.

\section{A R T I C L E I N F O}

\section{Article history:}

Received 3 March 2018

Received in revised form

30 May 2018

Accepted 31 May 2018

Available online 6 June 2018

Handling Editor: Jun Huang

\section{Keywords:}

Photocatalytic ozonation

Visible light

Grey water

Electrically enhanced membrane bioreactor

Nitrogen-doped titanium dioxide

\begin{abstract}
A B S T R A C T
Photocatalysis and photocatalytic ozonation under visible light have been applied for the purification of a complex aqueous matrix such as the grey water of Masdar City (UAE), by using N-doped brookite-rutile catalysts. Preliminary runs on 4-nitrophenol (4-NP) solutions allowed to test the reaction system in the presence of a model pollutant and to afford the relevant kinetic parameters of the process. Subsequently, the remediation of grey water effluent has been evaluated in terms of the reduction of total organic carbon (TOC) and bacterial counts. The concentration of the most abundant inorganic ionic species in the effluent has been also monitored during reaction. Photocatalytic ozonation under visible light allowed to reduce the TOC content of the grey water by ca. $60 \%$ in the optimized experimental conditions and to reduce the total bacterial count by ca. $97 \%$. The extent of TOC mineralization reached ca. $80 \%$ when the photocatalytic ozonation occurred downstream to a preliminary electro-membrane bioreactor (eMBR). Coupling the two processes enhanced the global efficiency. In fact, the eMBR treatment lowered the turbidity and the organic load of the effluent entering the photocatalytic ozonation treatment, which in turn enhanced the extent of purification and disinfection.
\end{abstract}

๑) 2018 Elsevier Ltd. All rights reserved.

\section{Introduction}

Photocatalysis has attracted considerable interest as a promising tool for environmental remediation (León et al., 2017; Ohno and Tsubota, 2010; Vilar et al., 2017). The oxidizing ability of this technology is due to the photogeneration of highly active radical species such as hydroxyl radicals, which unselectively degrade

\footnotetext{
* Corresponding author.

E-mail address: giovanni.palmisano@ku.ac.ae (G. Palmisano).
}

almost every organic pollutant with few exceptions (Kisch, 2014). Titanium dioxide $\left(\mathrm{TiO}_{2}\right)$ is the most used and studied photocatalyst to this aim. Indeed, its chemical (photo)stability, abundancy and low cost, along with the possibility of tailoring its properties according to the desired application, justify its widespread use in the relevant literature (Augugliaro et al., 2010; Dolat et al., 2013). At least three main issues limited so far large scale applications of $\mathrm{TiO}_{2}$ photocatalysis: (i) $\mathrm{TiO}_{2}$ is not able to absorb the visible fraction of the solar spectrum, (ii) photocatalytic runs on real complex matrices generally show low reaction rates, (iii) the process cost is 
not sufficiently competitive and the current technology still not mature for full scale applications in grey water treatment.

By taking into account that UV light only represents ca. $4 \%$ of the solar spectrum, extending the light harvesting ability of $\mathrm{TiO}_{2}$ to the visible range is highly desirable, as it would imply an efficient exploitation of solar energy. Different techniques have been proposed for $\mathrm{TiO}_{2}$ sensitization (Pelaez et al., 2012). Among them nitrogen doping combines versatile, easy and inexpensive preparation procedures, good visible light responsiveness and stability of the photocatalyst under irradiation. The second issue to be taken into account is related to the low reaction rates observed when photocatalysis is applied to real, complex aqueous matrices. The main factors affecting photocatalytic efficiency are high salinity and turbidity or high pollutants load. Salts dissolved in water drastically diminish the oxygen solubility with a major effect on the charge transfer mechanisms. On the other hand, turbidity reduces the transmittance of light through the suspension and the availability of photons as reactants. High organic load may as well influence the light distribution but also poison the photocatalyst by irreversibly occupying the active sites. To overcome these problems photocatalysis has been investigated as an integrated process with other advanced oxidation techniques (Ahmadi et al., 2015; GarciaSegura and Brillas, 2017; Tseng et al., 2012), with physical methods (Cataldo et al., 2016), or it has been applied as a tertiary wastewater treatment after a biological process (Bernabeu et al., 2011; Borges et al., 2014). One of the most promising methods is the integration of photocatalysis with ozonation (Parrino et al., 2014). It has been demonstrated that photocatalytic ozonation affords reaction rates higher than the sum of those obtained by considering the single technologies acting separately (Parrino et al., 2015). This is mainly due to the higher electrophilicity of ozone with respect to oxygen. In fact, generation of one hydroxyl radical requires three electrons (i.e. photons) in the presence of oxygen and only one electron in the presence of ozone (Agustina et al., 2005). Plenty of articles report photocatalytic ozonation for the degradation of model pollutants such as phenols (Ardizzone et al., 2011), formic acid (Wang et al., 2002) or methanol (Mena et al., 2012) among others. Fewer studies target the photocatalytic ozonation of real wastewater effluents, like winery wastewater (Gimeno et al., 2007) or reused water (Zou and Zhu, 2008). Even fewer are the investigations on photocatalytic ozonation under visible light for the degradation of pollutants such as pesticides (3,6-dichloro-2methoxybenzoic acid) (Maddila et al., 2016) and other compounds like oxalic acid (Mano et al., 2015; Pan et al., 2015) at laboratory scale.

To the best of our knowledge the use of photocatalytic ozonation under visible radiation for the treatment of real effluents such the one here investigated, has not been comprehensively studied earlier. A nitrogen-doped $\mathrm{TiO}_{2}\left(\mathrm{~N}-\mathrm{TiO}_{2}\right)$ sample, containing brookite and rutile phase, has been prepared according to Pikuda et al. (2017) and used for the present investigation. Our results have been compared to those obtained with the commercial $\mathrm{TiO}_{2}$ Evonik P25, which is widely considered a benchmark.

Given that visible photocatalytic ozonation has been rarely studied, in particular by using $\mathrm{N}$-doped $\mathrm{TiO}_{2}$, we have first investigated the possibility to perform such a treatment through the degradation of a model compound, which is 4-nitrophenol (4-NP), in order to assess the reaction conditions and to determine some relevant kinetic parameters. 4-NP is a stable, water soluble, biorecalcitrant compound, representing an issue for the environment and the public health and the photodegradation of which has been deeply studied in literature. After process optimization, the same visible light photocatalytic ozonation was applied to treat grey water collected in Masdar City (Abu Dhabi, UAE) and, finally, it was performed downstream to an electrically enhanced membrane bioreactor (eMBR). No reports in literature approached the coupling of advanced oxidation processes with eMBR for the treatment of raw grey water effluents. The eMBR is a combination of biological process, membrane filtration and electrokinetics (Giwa and Hasan, 2015a, 2015b, Hasan et al., 2014, 2012). This allows some electrochemical phenomena to happen such as electrocoagulation, electroosmosis and electrophoresis, enhancing the effectiveness of this treatment when compared with traditional membrane bioreactors (Ensano et al., 2016). The preliminary treatment by means of eMBR upstream to the photocatalytic ozonation process produced several advantages, thus increasing the efficiency of the global process as discussed throughout the paper.

\section{Experimental}

\subsection{Chemicals, catalysts and water}

All the chemicals were used as received without further purifications. The catalyst chosen for the present investigation was a $\mathrm{N}-\mathrm{TiO}_{2}$ sample (labeled as $0.8 \% \mathrm{~N}-\mathrm{TiO}_{2}$ ) obtained by a sol-gel method described by Pikuda et al. (2017). Briefly, Ti (IV) butoxide (Sigma Aldrich puriss. p.a.) was used as the titanium precursor in an acidic hydro-alcoholic solution in the presence of $\mathrm{HCl}$ (Sigma Aldrich, 37\%) and 2-propanol (Sigma Aldrich, puriss. p.a.). Ammonium nitrate (Sigma Aldrich, puriss. p.a.) was added as the nitrogen precursor in order to obtain $0.8 \%$ in weight of nitrogen doping in the final sample. This nitrogen content is reported by Pikuda to show the optimal photocatalytic performance. The photocatalyst obtained as a result of this preparation is a mixture of brookite (20\%), rutile (18.5\%), and amorphous phase (61.5\%) with a specific surface area (SSA) of $57.6 \mathrm{~m}^{2} \mathrm{~g}^{-1}$. For the sake of comparison, pure $\mathrm{TiO}_{2}$ Evonik P25 (ca. $80 \%$ anatase and $20 \%$ rutile phase, SSA: $50 \mathrm{~m}^{2} \mathrm{~g}^{-1}$ ) was used as a benchmark.

Prior to the photocatalytic treatment, the grey water was collected (on 18th May 2016), filtered in a vacuum pump system with a Whatman filter (pore size of $1.2 \mu \mathrm{m}$ ) and characterized. The characterization of the grey water before and after filtration is summarized in Table S1. Photocatalysis and/or ozonation runs were carried out only on filtered grey water.

Given the limited rate of photocatalytic reactions on untreated grey water, dilution was needed to assess the degradation results in a reasonable time. On the other hand, dilution was not necessary in the integrated system, i.e. when photocatalytic ozonation was performed downstream to the eMBR treatment.

\subsection{Photocatalytic reactor: setup and procedures}

A scheme of the experimental setup used for the reactivity tests is shown in Fig. 1. Runs were carried out in a pressurized semi-batch

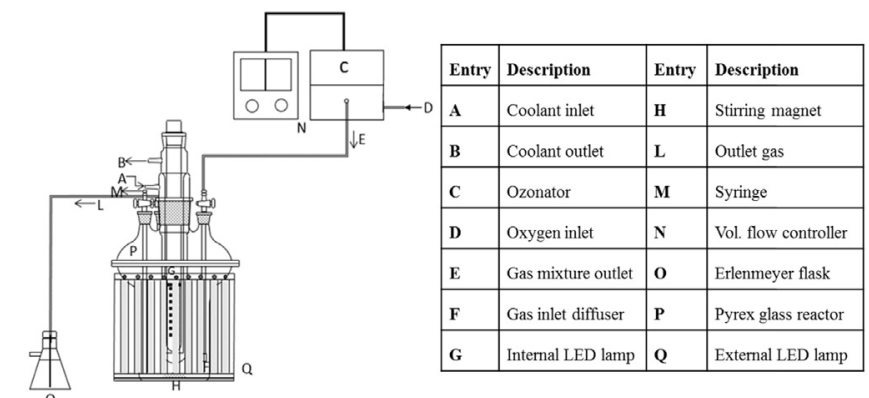

Fig. 1. Scheme and parts of the semi-batch reaction system used in the experiments. 
reactor of $0.75 \mathrm{~L}$ made of Pyrex glass, to ensure the transmittance of radiation through its walls. The parts of the reaction system are indicated with letters in Fig. 1.

The radiation sources were UV-free visible LED strips (SMD 3014) with the emission band between 425 and $750 \mathrm{~nm}$ (Fig. S1). The lamps were placed outside the external walls of the reactor and inside a housing of Pyrex glass immersed in the reacting suspension and surrounded by a jacket where recirculating cooling water ensured a constant operational temperature and prevented LED strips from overheating. The absorbed electric power of the internal and external lamps were 20.54 and $70.2 \mathrm{~W}$, respectively. The radiant power per unit surface of both internal and external LED systems was measured separately: the external one was $630 \mathrm{~W} \mathrm{~m}^{-2}$, measured at the external wall of the reactor, while the internal was $179 \mathrm{~W} \mathrm{~m}^{-2}$, measured at the external wall of the thimble containing the cooling fluid. The flow rate of oxygen bubbling through the suspension was set at $100 \mathrm{~mL} \mathrm{~min}^{-1}$ by using a mass flow controller (Bronkhorst F-201 CV) to ensure saturation of oxygen in the solution.

Ozone was produced from pure oxygen in an ozone generator (Aeraque Microlab 1AQ). The operating conditions of the generator were fixed in order to obtain an ozone concentration in the gaseous stream of $56.4 \mathrm{~g} \mathrm{~m}^{-3}$ (measured at 1 bar), corresponding to a total production of ozone of $1.7 \mathrm{~g} \mathrm{~h}^{-1}$ at the operating flowrate of the equipment $\left(0.4 \mathrm{~L} \mathrm{~min}^{-1}\right)$.

The amount of catalyst used in each run was $1.5 \mathrm{~g} \mathrm{~L}^{-1}$ for $0.8 \%$ $\mathrm{N}-\mathrm{TiO}_{2}$, at which the light transmittance measured at the external wall of the reactor was ca. $40 \%$ compared to the one in the absence of the catalyst; the catalyst amount was not further increased to prevent sedimentation. P25 was used with an amount of $0.85 \mathrm{~g} \mathrm{~L}^{-1}$, which produced a similar transmittance. This amount allowed to normalize the intensity of photons being absorbed and scattered by the suspension and to enable comparison of the results. The initial concentration of 4-NP ranged between 1 and $8 \mathrm{ppm}$ and the $\mathrm{pH}$ was the neutral one, i.e. ca. 6 . The suspension was sonicated for $10 \mathrm{~min}$ to ensure good dispersion of the catalyst and left under stirring in the presence of gas bubbling in dark conditions for $1 \mathrm{~h}$ in order to achieve thermodynamic adsorption-desorption equilibrium. To monitor dark adsorption, a sample of the initial solution was withdrawn before the ignition of the lamp. Once the lamps were switched on, samples were taken at fixed time intervals, filtered to separate the catalyst with PVDF syringe filters $(0.2 \mu \mathrm{m})$ and immediately analyzed.

\section{3. eMBR setup}

The eMBR treatment upstream to some photocatalytic ozonation runs was performed by means of a lab-scale continuous mode eMBR, designed by Giwa et al. (2015) and Hasan et al. (2014) for the treatment of municipal grey water collected from Masdar City at an effluent flow rate of $40 \mathrm{~L} \mathrm{~d}^{-1}$. The effective volume of the reacting liquid was $22.5 \mathrm{~L}$. The membrane employed was a flat sheet submerged microfiltration (MF) membrane with a pore size of $0.4 \mu \mathrm{m}$ supplied by KUBOTA Corporation. The material of the membrane consisted of acrylonitrile butadiene styrene (ABS), polypropylene (PP), polyethylene terephthalate, and chlorinated polyethylene at a proportion of $1: 2: 2: 2$. A constant current density of $10 \mathrm{~A} \mathrm{~m}^{-2}$ was maintained throughout the experiment by adjusting the voltage knob, and an intermittent current ( 5 min ON, 15 min OFF) was supplied by using an electronic timer. The chosen configuration was A-C-M-C-A (A stands for anode, C stands for cathode, and M stands for membrane). The anodes and cathodes were made of aluminum and stainless steel, respectively. The sludge inoculum was obtained from an MBR water treatment plant at Masdar City, with an initial average mixed liquor suspended solids (MLSS) of 2200 ppm.

\subsection{Analytical techniques}

A UV-VIS spectroscopy apparatus (Shimadzu UV-2600) at $315 \mathrm{~nm}$ and a TOC analyzer (Shimadzu TOC-L) were used to measure the 4-NP concentration and its mineralization degree, respectively. Preliminarily, a HPLC equipped with an Acclaim-120 C18 Reversed-phase LC column was used to verify that the absorbance recorded by the UV-VIS spectrophotometer at $315 \mathrm{~nm}$ gives true measurement of 4-NP concentration, without interferences resulting from organic oxidized intermediates, at a flowrate of $0.2 \mathrm{~mL} \mathrm{~min}^{-1}$ and with the following eluent: $33 \%$ water, $33 \%$ acetonitrile, $33 \%$ methanol, $1 \% 2 \mathrm{M}$ ammonium acetate. The reproducibility of the photocatalysis and/or ozonation runs was always over $95 \%$, replicated at least 2 times.

The purification extent of grey water was monitored by measuring the TOC content (Shimadzu TOC-L) of samples taken at fixed time intervals and by the total bacteria count (TBC) method. The latter analysis was carried out by the plate count agar method. The culture media, consisting of $10 \mathrm{~g}$ Tryptone, $5 \mathrm{~g}$ Yeast extract, $5 \mathrm{~g}$ $\mathrm{NaCl}$ and $15 \mathrm{~g}$ agar in $1 \mathrm{~L}$ water, were autoclaved for $15 \mathrm{~min}$ at $121^{\circ} \mathrm{C}$ to ensure the sterility and poured in the sterile petri dishes. An aliquot $(100 \mu \mathrm{L})$ of samples was cultured in LB agar plate for $48 \mathrm{~h}$ at $37^{\circ} \mathrm{C}$. Serial dilution was used to obtain more precise number of bacterial colonies defined as colony forming units (CFU) per $\mathrm{mL}$. The ions content was also analyzed by means of a Thermo Scientific Dionex ICS-5000 ion chromatograph.

\subsection{Kinetic assessment of 4-NP degradation}

The kinetics of 4-NP degradation were assessed through the Langmuir-Hinshelwood (L-H) model. Eq. (1) shows the general expression of the L-H kinetics:

$r_{H}=-\frac{1}{S} \frac{d n_{p}}{d t}=k^{\prime \prime} \theta_{p} \theta_{o}$

where the rate of reaction $r_{H}$ is a function of the fractional surface coverage of pollutant $\theta_{p}$ and the fractional surface coverage of the gas (oxygen or ozone) $\theta_{0}$, multiplied by a second order kinetic constant $k$ ". In the experimental conditions under which 4-NP was oxidized, saturation of gas in the aqueous media may be safely hypothesized, so that the fractional surface coverage of gas $\theta_{0}$ can be considered constant. Accordingly, a new pseudo first order constant $k$, product of $k$ " and $\theta_{0}$, can be defined as shown in Eq. (2), where the dependence on the reactor volume $V$, the specific surface area of the catalyst $S_{c}$, and the mass of catalyst $M$ have been introduced.

$r_{H}=-\frac{1}{S} \frac{d n_{p}}{d t}=-\frac{V}{S_{C} M} \frac{d C_{P}}{d t}=k \theta_{p}$

The fractional surface coverage of the pollutant (Eq. (3)) is a function of its concentration in the liquid phase $C_{p}$, experimentally obtained, of $K_{a}$, i.e. the adsorption constant of the pollutant on the catalyst, and of $C_{i}$ and $K_{i}$, which are analogously defined for the intermediate species generated during the reaction.

$$
\theta_{p}=\frac{K_{a} C_{p}}{1+K_{a} C_{p}+\Sigma K_{i} C_{i}}
$$

The concentration of intermediates $C_{i}$ is small due to the low concentration of pollutant and to the limited mineralization rate during the first stages of the reaction. Furthermore, the adsorption constants of the pollutant and of the intermediates, respectively $K_{a}$ and $K_{i}$, may be considered similar. Under these assumptions, Eq. (3) can be reduced to Eq. (4), where $C_{p, 0}$ is the initial concentration of 
pollutant. Notably, the fractional surface coverage of pollutant $\theta_{p}$ is known once $K_{a}$ is determined.

$\theta_{p}=\frac{K_{a} C_{p}}{1+K_{a} C_{p, 0}}$

By substituting this expression of $\theta_{p}$ in Eq. (2) one obtains Eq. (5), where the constant factors are grouped together and defined as $k_{\text {obs }}$.

$r_{H}=k \theta_{p}=k \frac{K_{a}}{1+K_{a} C_{p, 0}} C_{p}=k_{o b s} C_{p}$

Therefore, the reaction rate is determined once the apparent rate constant $k_{o b s}$ and the pollutant concentration in the aqueous medium $C_{p}$ are known. $\mathrm{k}_{\mathrm{obs}}$ is obtained by interpolating the initial rate from different experimental data while $C_{p}$ is experimentally measured.

The values of $k$ and $K_{a}$ may be determined by considering that

$\frac{1}{k_{o b s}}=\frac{1}{k K_{a}}+\frac{C_{P, 0}}{k}$

where all of the parameters, except the initial concentration of pollutant and $k_{o b s}$, are constant. Therefore, plotting the values of $1 /$ $k_{o b s} v s$. $C_{P, 0}$ obtained from runs at different initial 4-NP concentration and applying a linear best fitting procedure, $k$ and $K_{a}$ are obtained as slope and intercept, respectively.

By solving the differential Eq. (2) under the boundary condition $C_{P}=C_{P, 0}$ at $t=0$, Eq. (7) is obtained. The latter expresses the exponential decrease of the pollutant concentration during the reaction.

$C_{P}=C_{P, 0} e^{\left(-k_{o b s} t\right)}$

By adjusting the two parameters $K_{a}$ and $k$, the modeled $k_{o b s}$ values have been obtained by minimizing the sum of the quadratic errors calculated by difference with the correspondent values obtained from the experimental runs.

\section{Results and discussion}

\subsection{Photocatalytic ozonation of 4-NP solutions}

Preliminary tests have been carried out by treating deionized (DI) water containing 4-NP by means of photocatalysis, ozonation, and photocatalytic ozonation under visible light irradiation.

The benchmark photocatalyst P25 is not able to induce 4-NP degradation (Pikuda et al., 2017) as it cannot be activated by visible light. The influence of light intensity was checked by irradiating the reacting mixture only with the internal or with both internal and external LED visible lamps. The activity of the $0.8 \%$ $\mathrm{N}-\mathrm{TiO}_{2}$ in the presence of oxygen and ozone irradiated only by the internal LED visible lamps is shown in Fig. S2. Results are plotted in terms of concentration of 4-NP and TOC.

When only the internal lamps irradiated the suspension, the 4NP degradation macroscopically occurred at the same rate by photocatalysis or photocatalytic ozonation (ca. 40\% degradation after $10 \mathrm{~h}$ ). Similar trend may be observed by taking into account the corresponding TOC values. These results do not apparently agree with the reports of the relevant literature (Parrino et al., 2015) where generally the integration of ozonation and photocatalysis presents synergistic effects. In order to understand the reasons of such a result, the same runs with a higher 4-NP concentration $(5 \mathrm{ppm})$ were performed under both internal and external LED irradiation. Results are shown in Fig. 2. In this case the effect of

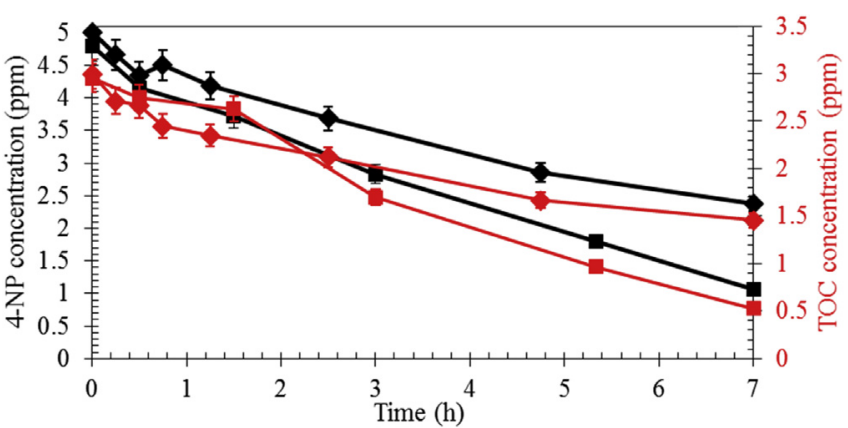

Fig. 2. 4-NP (black) and TOC (red) concentrations vs. time during photocatalysis (diamonds), and photocatalytic ozonation (squares) by using both external and internal irradiation systems. Initial 4-NP concentration: $5 \mathrm{ppm}$. (For interpretation of the references to colour in this figure legend, the reader is referred to the Web version of this article.)

photocatalytic ozonation becomes more evident. In fact, photocatalysis produced $52.5 \%$ 4-NP degradation, while $77.8 \%$ was achieved by means of photocatalytic ozonation after $7 \mathrm{~h}$ irradiation. Similar trend may be observed by taking into account the corresponding TOC values. The degradation of 4-NP was not observed in dark ozonation.

These results may be explained by considering the radiation field generated through the reacting suspension under the different irradiation conditions. In fact, the internal radiation system produces an intrinsically uneven radiative field due to the attenuation of the light along the radial direction (because of absorption and scattering phenomena) and to the punctual nature of the LED irradiation. On the other hand, the simultaneous external irradiation creates a more uniform radiative field by mitigating the above mentioned light intensity attenuation. The uniformity of the radiative field is a key factor for a correct kinetic analysis of a reacting irradiated suspension (Camera-Roda et al., 2017). Indeed, photons can be considered as reactants, and their concentration is generally not uniform due to the fact that they cannot be "mixed". It is important to stress that recently LED lamps have been widely used as irradiation sources for photocatalytic applications, due to their low cost, energy consumption, and good versatility. In the case of reactors irradiated only annularly, the local values of the relevant kinetic parameters, whose knowledge derives by the demanding solution of the radiative transport equation, significantly differ from the corresponding average values which, on the other hand, are the only ones experimentally accessible. Therefore, using the experimental values in this situation would generate an incorrect kinetic analysis. Camera-Roda et al. (2016) pointed out that the experimental values of the reaction rate closely approach the local ones, by increasing the uniformity of the radiant field and working at a low value of the suspension optical thickness. Accordingly, by using both internal and external visible light sources, the radiative field becomes more uniform and the reactor volume is more efficiently irradiated. In these conditions the $\mathrm{TiO}_{2}$ induced ozone activation becomes evident as shown in Fig. 2. The more electrophilic character of ozone with respect to oxygen makes it a better electron acceptor compared to oxygen, giving rise to ozonide radical anions according to Eq. (8). Incidentally, the advantage of having ozone rather than oxygen reacting with conduction band electrons might not be evident in those cases where Eq. (8) is not the reaction limiting step: such event occurs in the presence of a limited extent of conduction band electrons, which is likely if the photon flux is insufficient. The generated ozonide radical undergoes protonation (Eq. (9)) and yields oxygen and one hydroxyl radical per absorbed photon (Eq. (10)). 
$\mathrm{O}_{3}+\mathrm{e}^{-} \rightarrow \mathrm{O}_{3^{\bullet}}$

$\mathrm{O}_{3} \cdot-+\mathrm{H}^{+} \rightarrow \mathrm{HO}_{3} \cdot$

$\mathrm{HO}_{3} \cdot \rightarrow \mathrm{O}_{2}+\cdot \mathrm{OH}$

On the other hand three photons are required to produce one hydroxyl radical through oxygen reduction, as shown in Eqs. (11)-(14).

$3 \mathrm{O}_{2}+3 \mathrm{e}^{-} \rightarrow 3 \mathrm{O}_{2}{ }^{-}$

$2 \mathrm{O}_{2} \cdot^{-}+2 \mathrm{H}^{+} \rightarrow 2 \mathrm{HO}_{2} \cdot$

$2 \mathrm{HO}_{2} \cdot \rightarrow \mathrm{H}_{2} \mathrm{O}_{2}+\mathrm{O}_{2}$

$\mathrm{H}_{2} \mathrm{O}_{2}+\mathrm{O}_{2}{ }^{-} \rightarrow \cdot \mathrm{OH}+\mathrm{OH}^{-}+\mathrm{O}_{2}$

These considerations, often reported in the relevant literature (Agustina et al., 2005), justify the improved degradation efficiency of photocatalytic ozonation with respect to the separate technologies.

Once the irradiation conditions were optimized, the assessment of 4-NP oxidation was carried out by L-H kinetics applied to photocatalysis and photocatalytic ozonation, as detailed in the experimental section. Even if it is the most used model to assess the kinetics of photocatalytic reactions, L-H also presents a number of drawbacks, that have been highlighted in the past years by a number of scholars (Pelizzetti et al., 1993). One of the most common critical points is the saturation of the active sites which according to L-H model - should bring to a plateau in the reaction rate by increasing the initial concentration of the reactant, whereas experimental evidence often shows a continuous rate increase (Vione et al., 2005).

Furthermore, it is well known that photocatalytic experimental values may be satisfactorily fitted by various kinetic models. Therefore, it is worth to note that the kinetic parameters hereby provided do not possess certain physical significance and should be rather considered adjustable parameters useful for prediction purposes.

Fig. 3 and Fig. S3 show that the above discussed model satisfactorily describes experimental runs at different 4-NP initial concentration $(8,5,3$, and $1 \mathrm{ppm})$ for photocatalytic ozonation and photocatalysis, respectively. After $7 \mathrm{~h}$ photocatalysis afforded 4-NP

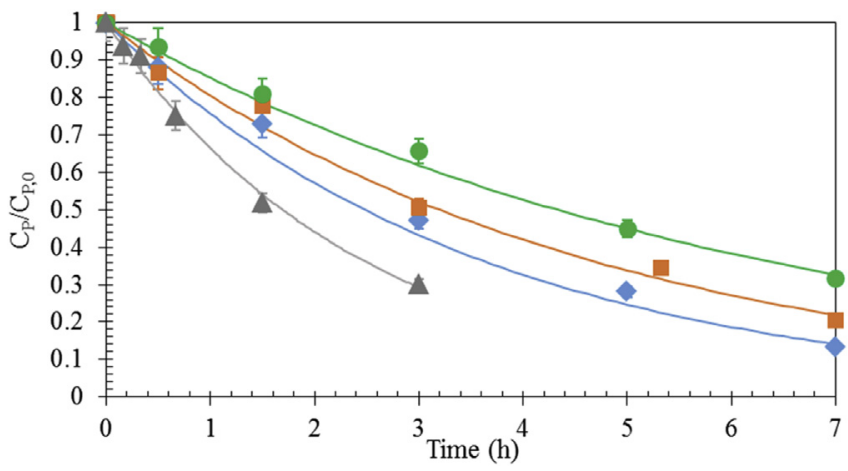

Fig. 3. Normalized 4-NP concentration vs time curves from the $\mathrm{L}-\mathrm{H}$ model and experimental points from the photocatalytic ozonation runs under internal and external visible light irradiation. Initial 4-NP concentrations: $8 \mathrm{ppm}$ (green circles), $5 \mathrm{ppm}$ (orange squares), $3 \mathrm{ppm}$ (blue diamonds) and $1 \mathrm{ppm}$ (grey triangles). Lines represent the L-H model. (For interpretation of the references to colour in this figure legend, the reader is referred to the Web version of this article.) degradation ranging between 49 and 76\%, while photocatalytic ozonation 69 and $87 \%$, depending on the initial 4-NP concentration.

The model yielded values of $k=8.63 \times 10^{-8} \mathrm{~mol} \mathrm{~m}^{-2} \mathrm{~h}^{-1}$ and $K_{a}=1.12 \times 10^{5} \mathrm{M}^{-1}$ for the photocatalytic treatment, and $k=1.73 \times 10^{-7} \mathrm{~mol} \mathrm{~m}^{-2} \mathrm{~h}^{-1}$ and $K_{a}=4.06 \times 10^{4} \mathrm{M}^{-1}$ for photocatalytic ozonation. Notably, the rate constant is almost doubled, while the 4-NP adsorption constant is one order of magnitude smaller when photocatalysis is performed in the presence of ozone with respect to oxygen.

Given the previous study on the samples of $\mathrm{TiO}_{2}$ here employed (Pikuda et al., 2017), the catalyst reusability has not been assessed in the present study.

\subsection{Photocatalytic ozonation of the grey water of Masdar City}

Photocatalytic ozonation under visible light in the presence of $0.8 \% \mathrm{~N}-\mathrm{TiO}_{2}$ has been performed on Masdar City grey water diluted in a ratio $1: 20$. Due to the complexity of the matrix the degradation of pollutants was monitored only in terms of TOC.

Preliminary tests demonstrated that the simultaneous presence of visible light and of the $0.8 \% \mathrm{~N}-\mathrm{TiO}_{2}$ photocatalyst was necessary for the reaction to occur (Fig. S4 and Fig. 4).

Indeed, irradiating the grey water but in the absence of $0.8 \%$ $\mathrm{N}-\mathrm{TiO}_{2}$ and with oxygen or ozone bubbling, did not produce appreciable TOC decrease during $12 \mathrm{~h}$ of treatment. Analogous results were obtained in dark conditions. Under visible light irradiation the benchmark photocatalyst P25 did not show any activity even in the presence of ozone, but it slowly released the organic impurities adsorbed on its surface, so that the TOC increased during time as shown in Fig. S4. Notably, when the catalyst was present in the reacting suspension, organics adsorbed almost instantaneously on its surface so that when the lamp was switched on the initial TOC value in the liquid phase was lower than for the runs in homogeneous phase (Fig. S4).

On the other hand, the TOC concentration of the grey water decreased by applying photocatalysis or photocatalytic ozonation under visible light irradiation and in the presence of $0.8 \% \mathrm{~N}^{-\mathrm{TiO}_{2}}$. Results are shown in Fig. 4.

Several runs were performed starting from different initial TOC concentrations obtained by varying the dilution ratio between 1:7.5 and 1:40. The TOC values against reaction time are displayed in Fig. 5 and Fig. S5, for photocatalytic ozonation and photocatalysis, respectively, in the presence of $0.8 \% \mathrm{~N}-\mathrm{TiO}_{2}$ and under visible light irradiation. It is possible to observe the initial increase of TOC

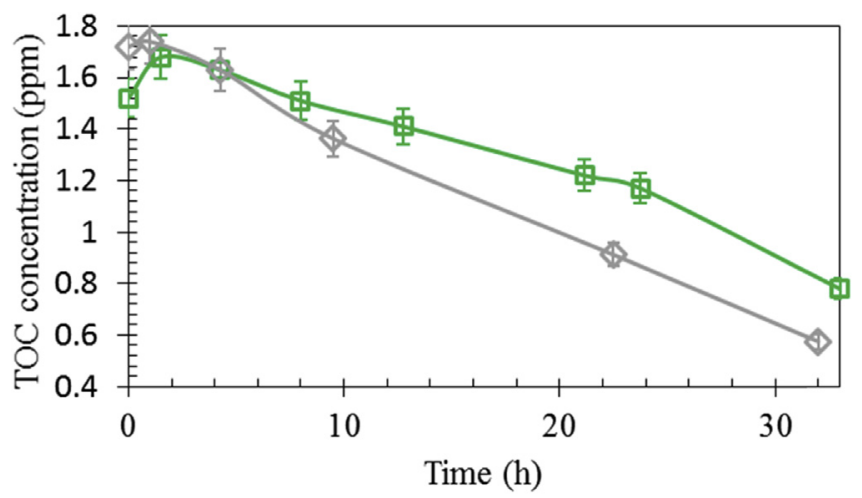

Fig. 4. TOC concentration vs time for the degradation of a grey water solution (diluted $1: 20$ ) through photocatalysis (green squares) and photocatalytic ozonation (grey diamonds) under internal and external visible light irradiation. (For interpretation of the references to colour in this figure legend, the reader is referred to the Web version of this article.) 


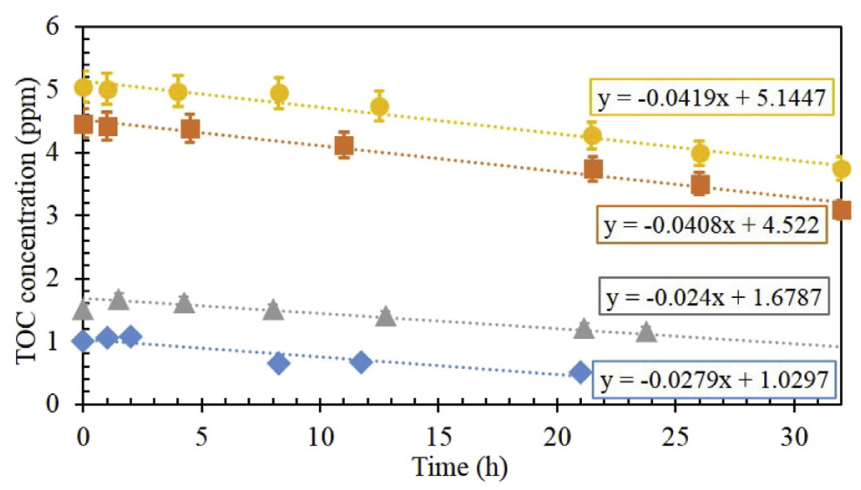

Fig. 5. TOC concentration vs time for the photocatalytic ozonation treatment of grey water under internal and external visible light irradiation. Dilution ratios: 1:7.5 (circles), 1:10 (squares), 1:20 (triangles) and 1:40 (diamonds).

concentration soon after switching on the light, because of photodesorption of species previously adsorbed in the dark stage, in agreement with previous literature (Boyjoo et al., 2012; El Saliby et al., 2012; Hidaka et al., 2010). This behavior could not be satisfactorily predicted by means of a proper kinetic model due to the complexity of the matrix and to the specific surface features generated upon light induced excitation of the photocatalyst.

The highest TOC decrease was $25.7 \%$ in the case of photocatalysis applied to a 1:7.5 diluted grey water and $54.9 \%$ for the photocatalytic ozonation treatment on a 1:40 diluted matrix. Fig. 5 and Fig S5 also show the different trends obtained at different initial concentrations.

The complexity of the grey water matrix and the photodesorption phenomena occurring soon after the start of irradiation did not allow for the application of the Langmuir-Hinshelwood model successfully by using the TOC trends.

The effect of photocatalytic ozonation was tested by a total bacteria count (TBC) analysis, performed before and after the treatments of photocatalytic ozonation. The bacterial amount in the 1:20 diluted grey water sample was found to be $3.75 \times 10^{4} \mathrm{CFU}$ $\mathrm{mL}^{-1}$. After $32 \mathrm{~h}$ of photocatalytic ozonation treatment, the TBC count was found to decrease to $10 \mathrm{CFU} \mathrm{mL} \mathrm{m}^{-1}$. The reactive oxygen species produce a loss of cell membrane potential causing oxidative damage to cellular components and finally inducing the lysis of the microorganisms (Mecha et al., 2017). This result is significant as it implies that photocatalytic ozonation not only allows for the abatement of the organic load in grey water but also promotes the disinfection of the effluent and offers the possibility of water reuse. It is worth noting that, in the absence of ozone, no decrease in the TBC was achieved.

In order to get information on the levels of the inorganic species present in the grey water, ion chromatography was performed at different intervals of time during the photocatalysis and photocatalytic ozonation runs. This analysis is relevant as some inorganic species present in the grey water or formed upon ozonation have high toxicity. This is the case of ammonia or bromate ions. In particular, bromate ions are generated by ozone-induced oxidation of bromide ions and they represent a great concern due to their toxic, mutagenic, and carcinogenic effects. Indeed, the suggested exposure safety value of bromate is 3 ppm (Hutchinson et al., 1997) and the concentrations in drinking water associated with upperbound excess lifetime cancer risks of $10^{-4}, 10^{-5}$, and $10^{-6}$ are 20 , 2 and $0.2 \mathrm{ppb}$, respectively (U.S. EPA, 2001).

Fig. S6 shows the concentration of selected ions during photocatalytic ozonation runs. Results obtained for the photocatalytic treatment are reported too (Fig. S7), and they are similar to those hereby reported for the photocatalytic ozonation, as far as the formation of sulphate, nitrate and ammonia are concerned.

Photocatalytic ozonation promotes the oxidation of the inorganic ions present in water to higher oxidation states (Parrino et al., 2015). This is the case of sulphur or bromine containing compounds which are oxidized to sulphate and bromate, respectively. As above mentioned, while sulphate ions do not pose relevant environmental or health problems, this is not the case of bromate ions. Parrino et al. (2015) proposed a strategy assessment by alternating photocatalytic ozonation and photocatalysis in order to control the production of bromate. Similar approach may be used also in this case, although this problem is beyond the scope of the present work.

Calcium is already in its highest oxidation state but its concentration decreased during photocatalytic ozonation. This is probably due to the binding of $\mathrm{Ca}^{2+}$ on the $\mathrm{TiO}_{2}$ surface reported in literature (Tang et al., 2010), since the precipitation of alkali compounds can be ruled out in the present case given that the $\mathrm{pH}$ of grey water is ca. 5.0 (Table S1).

The behavior of nitrogen species is more complex and depends on different factors such as $\mathrm{pH}$, temperature and the interaction of nitrogen species with other metabolites, as reported by the relevant literature (Zhu et al., 2005). Fig. S6 (B) shows that whereas the initial concentration of ammonium ion was very small, $0.006 \mathrm{ppm}$, it increased during the photocatalytic ozonation runs. The low concentration of ammonium ions can be due to the presence of bacteria in the grey water, especially nitrifying bacteria. Ammonium is in fact the preferred nitrogen source for most of the bacteria, despite of its cytotoxicity, and it passes across the bacterial cell membrane thanks to the ammonium transport (Amt) family of proteins (Müller et al., 2006). However, during the photocatalytic ozonation runs, we observed an increase in the concentration of ammonium, which may be related to the lysis of bacteria above mentioned, rather than to reactions directly related to photocatalytic ozonation. Accordingly, the metabolic products generated and stored by the bacteria present in the grey water might be released in the aqueous medium once the microorganisms are destroyed by photocatalytic ozonation. This hypothesis is also supported by the above reported TBC results. Moreover, while the concentration of nitrate ions increased, the concentration of nitrite ions decreased during the photocatalytic ozonation runs, highlighting how the photocatalytic oxidation of ammonium ions produces nitrite and nitrate via series reactions, as reported in literature (Zhu et al., 2005).

\section{3. eMBR-photocatalytic ozonation integrated system}

Selected photocatalytic ozonation runs were carried out on grey water previously treated by means of eMBR accordingly to a previous report (Hasan et al., 2014). The effluent downstream to the eMBR treatment was characterized and its main characteristics are summarized in Table S2.

Samples of raw municipal grey water were collected from Masdar City and were firstly treated by the eMBR (as a secondary treatment) before photocatalytic ozonation (as a tertiary treatment). The concentration of pollutants in the grey water feed was $420 \pm 130 \mathrm{ppm}, \quad 4.2 \pm 3.0 \mathrm{ppm}, \quad 14.6 \pm 7.4 \mathrm{ppm}, 1.95 \pm 0.5 \mathrm{ppm}$, $2.7 \pm 0.3 \mathrm{ppm}$ of $\mathrm{COD}, \mathrm{PO}_{4}^{3-}, \mathrm{NH}_{4}^{+}, \mathrm{Zn}$, and $\mathrm{Fe}$, respectively. The removal of $\mathrm{COD}, \mathrm{PO}_{4}^{3-}, \mathrm{NH}_{4}^{+}, \mathrm{Fe}$, and $\mathrm{Zn}$ were reported to be $94.8 \pm 1.4 \%, 97.1 \pm 2.1 \%, 83.7 \pm 5.8 \%, 95.2 \pm 0.7$, and $98.8 \pm 0.3 \%$, respectively, after eMBR treatment operated at a current density of $10 \mathrm{~A} \mathrm{~m}^{-2}$. eMBR effluent composition was $23.0 \pm 4.2 \mathrm{ppm}, 1.3 \pm 0.7$ ppm, $2.5 \pm 0.7 \mathrm{ppm}, 0.11 \pm 0.03 \mathrm{ppm}$, and $0.03 \pm 0.02 \mathrm{ppm}$ of COD, $\mathrm{PO}_{4}^{3-}, \mathrm{NH}_{4}^{+}, \mathrm{Zn}$, and Fe, respectively (Ahmed and Hasan, 2017).

The eMBR treatment produced a drastic decrease of the TOC 
concentration so that further dilution prior to photocatalytic ozonation was not required. Photocatalysis and photocatalytic ozonation were performed on this effluent in the presence of $0.8 \%$ $\mathrm{N}-\mathrm{TiO}_{2}$ under visible light irradiation. The TOC concentration profile during irradiation is shown in Fig. 6.

Around $60 \%$ and $74 \%$ of mineralization were achieved after $5 \mathrm{~h}$ of treatment with photocatalysis and photocatalytic ozonation, respectively. By comparing these results with those obtained without the preliminary membrane treatment, it can be concluded that photocatalysis and photocatalytic ozonation are more efficient if applied downstream to an eMBR treatment. This is mainly due to the fact that eMBR process limits the turbidity of the stream and significantly abates the organic load of the stream. On the other hand, photocatalysis and photocatalytic ozonation allow for a deeper level of depuration and disinfection to be reached with respect to the sole eMBR with a minimum energy surplus. In fact, these processes may be activated by cheap and abundant solar light which is mainly constituted by visible light (Garlisi et al., 2015). Furthermore, the combination of the two technologies allowed for the treatment of the grey water without any dilution, thereby offering an opportunity in terms of costs and water consumption.

These preliminary results on coupling eMBR and photocatalysis or photocatalytic ozonation are promising and further investigations are ongoing in order to improve their integration degree and enhance the overall process efficiency.

\subsection{Open issues and future developments}

Even if this study demonstrated the possibility to perform photocatalytic ozonation under UV-free visible radiation to treat grey water, in particular downstream to an eMBR unit, some issues remain open and further advances are needed to elevate the proof of concept to applications. First of all, an optimization of the whole system would be required to make the process attractive from a practical point of view: it is possible to work on catalyst loading, light radiation intensity, ozone concentration and the reactor itself to minimize reaction time. With regards to ozonation, the optimization of the amount of required ozone and of the intensification between the two considered technologies could give rise to significant operative costs reduction.

A relevant point to be addressed is the ability of photocatalytic ozonation to abate trace amounts of contaminants of environmental concern, which are recalcitrant to biological treatment and require a detailed chemical characterization of the matrix and suitable monitoring techniques. Fig. 6 shows that the difference in

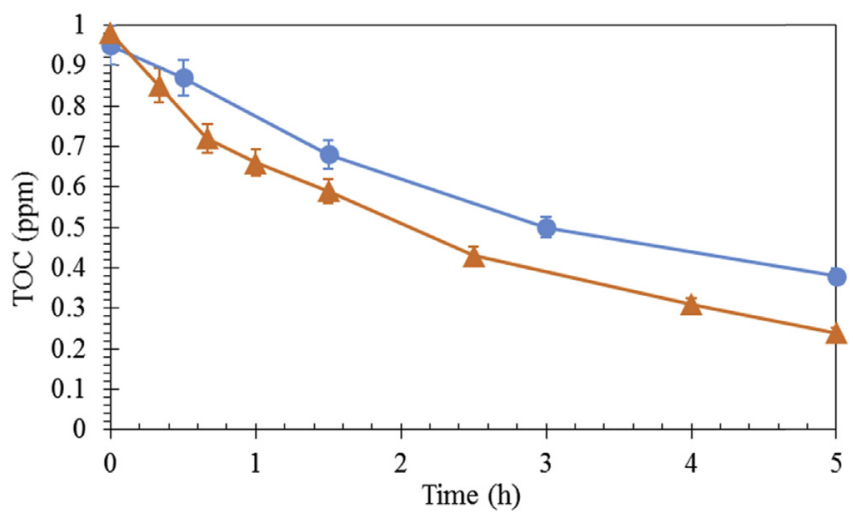

Fig. 6. TOC variation vs time for the photocatalytic (blue circles) and photocatalytic ozonation (orange triangles) of an eMBR effluent under internal and external visible light irradiation. (For interpretation of the references to colour in this figure legend, the reader is referred to the Web version of this article.) performance of the systems run with and without ozone is limited by looking at TOC abatement; however, the effects on recalcitrant pollutants present in traces in the water effluent can be drastic. Further studies are needed towards this direction. Moreover, even if TOC values directly relate the efficiency of the treatment with the presence of organic carbon, being appropriate in the present scientific report, the current legislation requires to compare indirect parameters such as BOD (biochemical oxygen demand) and/or COD (chemical oxygen demand) with the imposed limits for effluent disposal or reuse. This issue must be considered in future reports mainly addressed to the technical assessment of the proposed technology. The economic implications of a tertiary treatment downstream to a biological one must be also taken into account and decision on whether implementing it must be taken based on the characteristics of the treated effluent and its final fate, by addressing the cost of ozone in the overall balance.

\section{Conclusions}

Photocatalysis and photocatalytic ozonation were applied to the purification and disinfection of the grey water of Masdar City. Preliminary results on 4-NP solutions highlighted the essential role of a uniform radiative field distribution and allowed to set the operative conditions for the treatment of grey water. Photocatalytic ozonation under visible light allowed for decreasing the TOC content of grey water up to $60 \%$ and to reduce of ca. $97 \%$ the total bacterial load. The extent of purification reached ca. $80 \%$ if the photocatalytic ozonation occurred downstream to a preliminary electro-membrane bioreactor (eMBR). Coupling the two processes enhanced the global efficiency. In fact, the eMBR treatment decreases the turbidity and the organic load of the effluent entering the photocatalytic ozonation treatment which in turn enhances the extent of purification and disinfection. The presented results are promising and probably worth of further investigations with regard to their practical implications, as detailed in the previous section.

\section{Acknowledgments}

Authors would like to thank Masdar Institute of Science and Technology (now part of Khalifa University of Science and Technology) for financial support (Grant No. SSG2015-000024). Our appreciation also goes to Dr. L. F. Yousef and Dr. A. F. Yousef (Khalifa University of Science and Technology) for enabling the use of their lab facilities to carry out the TBC analysis.

\section{Appendix A. Supplementary data}

Supplementary data related to this article can be found at https://doi.org/10.1016/j.chemosphere.2018.05.197.

\section{References}

Agustina, T.E., Ang, H.M., Vareek, V.K., 2005. A review of synergistic effect of photocatalysis and ozonation on wastewater treatment. J. Photochem. Photobiol. C Photochem. Rev. 6, 264-273. https://doi.org/10.1016/j.jphotochemrev.2005.12. 003.

Ahmadi, M., Ghanbari, F., Moradi, M., 2015. Photocatalysis assisted by peroxymonosulfate and persulfate for benzotriazole degradation: effect of $\mathrm{pH}$ on sulfate and hydroxyl radicals. Water Sci. Technol. 72, 2095-2102. https://doi. org/10.2166/wst.2015.437.

Ahmed, M.A., Hasan, S.W., 2017. Fe and Zn removal from industrial wastewater using electrically-enhanced membrane bioreactor. Desalin. Water Treat. 93, 9-21. https://doi.org/10.5004/dwt.2017.21305.

Ardizzone, S., Cappelletti, G., Meroni, D., Spadavecchia, F., 2011. Tailored $\mathrm{TiO}_{2}$ layers for the photocatalytic ozonation of cumylphenol, a refractory pollutant exerting hormonal activity. Chem. Commun. 47, 2640-2642. https://doi.org/10.1039/ c0cc05134a.

Augugliaro, V., Loddo, V., Pagliaro, M., Palmisano, G., Palmisano, L., 2010. Clean by Light Irradiation. Royal Society of Chemistry, Cambridge. https://doi.org/10. 
1039/9781849732031.

Bernabeu, A., Vercher, R.F., Santos-Juanes, L., Simón, P.J., Lardín, C., Martínez, M.A. Vicente, J.A., González, R., Llosá, C., Arques, A., Amat, A.M., 2011. Solar photocatalysis as a tertiary treatment to remove emerging pollutants from wastewater treatment plant effluents. Catal. Today 161, 235-240. https://doi.org/10. 1016/J.CATTOD.2010.09.025.

Borges, M.E., Hernández, T., Esparza, P., 2014. Photocatalysis as a potential tertiary treatment of urban wastewater: new photocatalytic materials. Clean Technol. Environ. Policy 16, 431-436. https://doi.org/10.1007/s10098-013-0637-z.

Boyjoo, Y., Ang, M., Pareek, V., 2012. Photocatalytic treatment of shower water using a pilot scale reactor. Int. J. Photoenergy 2012,1-7. https://doi.org/10.1155/2012/ 578916.

Camera-Roda, G., Augugliaro, V., Cardillo, A.G., Loddo, V., Palmisano, L., Parrino, F., Santarelli, F., 2016. A reaction engineering approach to kinetic analysis of photocatalytic reactions in slurry systems. Catal. Today 259, 87-96. https://doi. org/10.1016/i.cattod.2015.05.007.

Camera-Roda, G., Loddo, V., Palmisano, L., Parrino, F., 2017. Guidelines for the assessment of the rate law of slurry photocatalytic reactions. Catal. Today 281 221-230. https://doi.org/10.1016/j.cattod.2016.06.050.

Cataldo, S., Ianni, A., Loddo, V., Mirenda, E., Palmisano, L., Parrino, F., Piazzese, D., 2016. Combination of advanced oxidation processes and active carbons adsorption for the treatment of simulated saline wastewater. Separ. Purif. Technol. 171, 101-111. https://doi.org/10.1016/j.seppur.2016.07.026.

Dolat, D., Mozia, S., Ohtani, B., Morawski, A.W., 2013. Nitrogen, iron-single modified $\left(\mathrm{N}-\mathrm{TiO}_{2}, \mathrm{Fe}-\mathrm{TiO}_{2}\right)$ and co-modified $\left(\mathrm{Fe}, \mathrm{N}-\mathrm{TiO}_{2}\right)$ rutile titanium dioxide as visiblelight active photocatalysts. Chem. Eng. J. 225, 358-364. https://doi.org/10.1016/ J.CEJ.2013.03.047.

El Saliby, I., Shahid, M., McDonagh, A., Shon, H.K., Kim, J.-H., 2012. Photodesorption of organic matter from titanium dioxide particles in aqueous media. J. Ind. Eng. Chem. 18, 1774-1780. https://doi.org/10.1016/J.JIEC.2012.04.002.

Ensano, B.M.B., Borea, L., Naddeo, V., Belgiorno, V., de Luna, M.D.G., Ballesteros, F.C., 2016. Combination of electrochemical processes with membrane bioreactors for wastewater treatment and fouling control: a review. Front. Environ. Sci. 4, 57. https://doi.org/10.3389/fenvs.2016.00057.

Garcia-Segura, S., Brillas, E., 2017. Applied photoelectrocatalysis on the degradation of organic pollutants in wastewaters. J. Photochem. Photobiol. C Photochem. Rev. 31, 1-35. https://doi.org/10.1016/j.jphotochemrev.2017.01.005.

Garlisi, C., Scandura, G., Alabi, A., Aderemi, O., Palmisano, G., 2015. Self-cleaning coatings activated by solar and visible radiation. J. Adv. Chem. Eng. 5. https:// doi.org/10.4172/2090-4568.1000e103.

Gimeno, O., Rivas, F.J., Beltrán, F.J., Carbajo, M., 2007. Photocatalytic ozonation of winery wastewaters. J. Agric. Food Chem. 55, 9944-9950. https://doi.org/10. 1021 /jf072167i.

Giwa, A., Ahmed, I., Hasan, S.W., 2015. Enhanced sludge properties and distribution study of sludge components in electrically-enhanced membrane bioreactor. J. Environ. Manag. 159, 78-85. https://doi.org/10.1016/j.jenvman.2015.05.035.

Giwa, A., Hasan, S.W., 2015a. Numerical modeling of an electrically enhanced membrane bioreactor (MBER) treating medium-strength wastewater. J. Environ. Manag. 164, 1-9. https://doi.org/10.1016/j.jenvman.2015.08.031.

Giwa, A., Hasan, S.W., 2015b. Theoretical investigation of the influence of operating conditions on the treatment performance of an electrically-induced membrane bioreactor. J. Water Process Eng. 6, 72-82. https://doi.org/10.1016/j.jwpe.2015. 03.004.

Hasan, S.W., Electorowicz, M., Oleszkiewicz, J.A., 2014. Start-up period investigation of pilot-scale submerged membrane electro-bioreactor (SMEBR) treating raw municipal wastewater. Chemosphere 97, 71-77. https://doi.org/10.1016/j. chemosphere.2013.11.009.

Hasan, S.W., Elektorowicz, M., Oleszkiewicz, J.A., 2012. Correlations between transmembrane pressure (TMP) and sludge properties in submerged membrane electro-bioreactor (SMEBR) and conventional membrane bioreactor (MBR) Bioresour. Technol. 120, 199-205. https://doi.org/10.1016/j.biortech.2012.06. 043.

Hidaka, H., Oyama, T., Horiuchi, T., Koike, T., Serpone, N., 2010. Photo-induced oxidative synergistic degradation of mixed anionic/cationic surfactant systems in aqueous dispersions. A detailed study of the DBS/HTAB system. Appl. Catal. B Environ. 99, 485-489. https://doi.org/10.1016/J.APCATB.2010.06.041.

Hutchinson, T.H., Hutchings, M.J., Moore, K.W., 1997. A Review of the effects of bromate on aquatic organisms and toxicity of bromate to oyster (Crassostrea gigas) embryos. Ecotoxicol. Environ. Saf. 38, 238-243. https://doi.org/10.1006 eesa.1997.1584.

Kisch, H., 2014. Semiconductor Photocatalysis: Principles and Applications. WileyVCH Verlag GmbH \& Co. KGaA, Weinheim, Germany. https://doi.org/10.1002 9783527673315.ch1.

León, D.E., Zúñiga-Benítez, H., Peñuela, G.A., Mansilla, H.D., 2017. Photocatalytic removal of the antibiotic cefotaxime on $\mathrm{TiO} 2$ and $\mathrm{ZnO}$ suspensions under simulated sunlight radiation. Water, Air, Soil Pollut. 228, 361. https://doi.org/10. 1007/s11270-017-3557-4.

Maddila, S., Oseghe, E.O., Jonnalagadda, S.B., 2016. Photocatalyzed ozonation by Ce doped $\mathrm{TiO}_{2}$ catalyst degradation of pesticide Dicamba in water. J. Chem. Technol. Biotechnol. 91, 385-393. https://doi.org/10.1002/jctb.4583.

Mano, T., Nishimoto, S., Kameshima, Y., Miyake, M., 2015. Water treatment efficacy of various metal oxide semiconductors for photocatalytic ozonation under UV and visible light irradiation. Chem. Eng. J. 264, 221-229. https://doi.org/10. 1016/j.cej.2014.11.088.

Mecha, A.C., Onyango, M.S., Ochieng, A., Momba, M.N.B., 2017. Evaluation of synergy and bacterial regrowth in photocatalytic ozonation disinfection of municipal wastewater. Sci. Total Environ. 601-602, 626-635. https://doi.org/10.1016/J. SCITOTENV.2017.05.204.

Mena, E., Rey, A., Acedo, B., Beltrán, F.J., Malato, S., 2012. On ozone-photocatalysis synergism in black-light induced reactions: oxidizing species production in photocatalytic ozonation versus heterogeneous photocatalysis. Chem. Eng. J. 204-206, 131-140. https://doi.org/10.1016/j.cej.2012.07.076.

Müller, T., Walter, B., Wirtz, A., Burkovski, A., 2006. Ammonium toxicity in bacteria. Curr. Microbiol. 52, 400-406. https://doi.org/10.1007/s00284-005-0370-x.

Ohno, T., Tsubota, T., 2010. Development and sensitization of $\mathrm{N}-$ or S-Doped $\mathrm{TiO}_{2}$ photocatalysts. In: Environmentally Benign Photocatalysts. Springer, New York, NY, pp. 253-275. https://doi.org/10.1007/978-0-387-48444-0_11.

Pan, Z., Cai, Q., Luo, Q., Li, X., 2015. Photocatalytic ozonation of oxalic acid over $\mathrm{Cu}(\mathrm{II})$-Grafted $\mathrm{TiO}_{2}$ under visible light irradiation. Synth. React. Inorg. Met. Nano Metal Chem. 45, 447-450. https://doi.org/10.1080/15533174.2013.841207.

Parrino, F., Camera-Roda, G., Loddo, V., Augugliaro, V., Palmisano, L., 2015. Photocatalytic ozonation: maximization of the reaction rate and control of undesired by-products. Appl. Catal. B Environ. 178, 37-43. https://doi.org/10.1016/j.apcatb. 2014.10.081.

Parrino, F., Camera-Roda, G., Loddo, V., Palmisano, G., Augugliaro, V., 2014. Combination of ozonation and photocatalysis for purification of aqueous effluents containing formic acid as probe pollutant and bromide ion. Water Res. 50, 189-199. https://doi.org/10.1016/j.watres.2013.12.001.

Pelaez, M., Nolan, N.T., Pillai, S.C., Seery, M.K., Falaras, P., Kontos, A.G., Dunlop, P.S.M., Hamilton, J.W.J., Byrne, J.A., O'Shea, K., Entezari, M.H., Dionysiou, D.D., 2012. A review on the visible light active titanium dioxide photocatalysts for environmental applications. Appl. Catal. B Environ. 125, 331-349. https://doi.org/10. 1016/j.apcatb.2012.05.036.

Pelizzetti, E., Minero, C., Borgarello, E., Tinucci, L., Serpone, N., 1993. Photocatalytic activity and selectivity of titania colloids and particles prepared by the sol-gel technique: photooxidation of phenol and atrazine. Langmuir 9, 2995-3001. https://doi.org/10.1021/la00035a043.

Pikuda, O., Garlisi, C., Scandura, G., Palmisano, G., 2017. Micro-mesoporous N-doped brookite-rutile $\mathrm{TiO}_{2}$ as efficient catalysts for water remediation under UV-free visible LED radiation. J. Catal. 346, 109-116. https://doi.org/10.1016/j.jcat.2016. 12.010 .

Tang, F., Xu, B., Shi, H., Qiu, J., Fan, Y., 2010. The poisoning effect of $\mathrm{Na}^{+}$and $\mathrm{Ca}^{2+}$ ions doped on the $\mathrm{V}_{2} \mathrm{O}_{5} / \mathrm{TiO}_{2}$ catalysts for selective catalytic reduction of $\mathrm{NO}$ by $\mathrm{NH}_{3}$. Appl. Catal. B Environ. 94, 71-76. https://doi.org/10.1016/j.apcatb.2009.10.022.

Tseng, D.-H., Juang, L.-C., Huang, H.-H., 2012. Effect of oxygen and hydrogen peroxide on the photocatalytic degradation of monochlorobenzene in $\mathrm{TiO}_{2}$ aqueous suspension. Int. J. Photoenergy 2012, 1-9. https://doi.org/10.1155/ 2012/328526.

U.S. EPA, 2001. Toxicology Review of Bromate (CAS No. 15541-45-4) in Support of Integrated Risk Information System. IRIS, Washington, DC.

Vilar, V.J.P., Amorim, C.C., Li Puma, G., Malato, S., Dionysiou, D.D., 2017. Intensification of photocatalytic processes for niche applications in the area of water, wastewater and air treatment. Chem. Eng. J. 310, 329-330. https://doi.org/10. 1016/j.cej.2016.11.131.

Vione, D., Minero, C., Maurino, V., Carlotti, M.E., Picatonotto, T., Pelizzetti, E., 2005. Degradation of phenol and benzoic acid in the presence of a TiO2-based heterogeneous photocatalyst. Appl. Catal. B Environ. 58, 79-88. https://doi.org/10. 1016/J.APCATB.2004.11.018.

Wang, S., Shiraishi, F., Nakano, K., 2002. A synergistic effect of photocatalysis and ozonation on decomposition of formic acid in an aqueous solution. Chem. Eng. J. 87, 261-271. https://doi.org/10.1016/S1385-8947(02)00016-5.

Zhu, X., Castleberry, S.R., Nanny, M.A., Butler, E.C., 2005. Effects of pH and catalyst concentration on photocatalytic oxidation of aqueous ammonia and nitrite in titanium dioxide suspensions. Environ. Sci. Technol. 39, 3784-3791.

Zou, L., Zhu, B., 2008. The synergistic effect of ozonation and photocatalysis on color removal from reused water. J. Photochem. Photobiol. Chem. 196, 24-32. https:// doi.org/10.1016/j.jphotochem.2007.11.008. 